\title{
Implicações da moral religiosa e dos pressupostos científicos na construção das representações do corpo e da sexualidade femininos no Brasil**
}

Kelma Lima Cardoso Leite**

\section{Resumo}

Este artigo pretende discutir, na perspectiva de gênero, as reverberações da moral religiosa e do saber científico no processo de construção das representações do corpo e da sexualidade femininos no Brasil. A questão mais relevante que se coloca é como as comunidades religiosas e científica estabeleceu o regime de verdade e o modelo de razão que deu sentido aos corpos sexualizados femininos no transcurso do devir histórico? A resposta à pergunta foi obtida a partir de análise e exposição de um arcabouço teórico multidisciplinar que destaca as contribuições da história, psicologia, sociologia e filosofia.

Palavras-chave: Corpo, Sexualidade, Feminino, Religião e Ciência.

" Recebido em 28 de janeiro de 2015, aceito em 13 de novembro de 2015.

*** Professora do departamento de Ciências Sociais, da Universidade Federal do Ceará, Fortaleza. CE, Brasil. kelma.leite@hotmail.com 
Implications of Moral Religious and Scientific Assumptions in Construction of Representations of the Body and Female Sexuality in Brazil

\begin{abstract}
The article discusses, in a gender perspective, the reverberations of religious moral and scientific knowledge in the construction of representations of body and female sexuality in Brazil. The most important question that arises is how the religious and scientific community established the regime of truth and model of reason gave meaning to female sexualized bodies in the course of historical development? The answer to the question was obtained from the analysis and display of a multidisciplinary theoretical framework that highlights the contributions of history, psychology, sociology and philosophy.
\end{abstract}

Key Words: Body, Sex, Women, Religion and Science. 
Embora o corpo físico seja o habitat da sexualidade $e$ demarcador das fronteiras daquilo que é sexualmente possível, a sexualidade é mais do que simplesmente matéria corporal e está amalgamada a nossas crenças, ideologias e imaginação (Weeks, 2001:38). Machos e fêmeas biológicos são igualmente submetidos a processos de sociabilização sexual no qual representações culturalmente específicas de masculinidade e feminilidade são modeladas no transcurso da vida.

Neste artigo, tal corpo físico-psíquico ou sexualizado foi percebido de maneira mais complexa em sua singularidade, isto é, o enfoque teórico limitou-se às questões referentes às mulheres, afinal, do corpo e da sexualidade feminina dependem muitas coisas importantes para o Estado e a ciência, a saber, a reprodução da espécie humana e o avanço de determinadas patologias sexualmente transmissiveis.

Considerando ainda que a dimensão material e psíquica do corpo da mulher foi marcada como que por uma espécie de tatuagem físico-simbólica, julgou-se pertinente o recuo "no tempo à procura do regime de verdade, do modelo de razão que nos construiu dessa maneira, que deu certo sentido a nossos corpos sexualizados" (Colling, 2004:51). Com essas questões em mente é que se pode dizer que o binômio corpo e sexualidade, cerne de uma preocupação individual e foco de uma discussão claramente crítica e científica, merece uma investigação teórica multidisciplinar pautada em autores de áreas afins de conhecimento, a saber, história, psicologia, sociologia e filosofia.

\section{Os interditos da Igreja atuando sobre o corpo e a sexualidade feminina}

No Brasil, entre os séculos XVI e XVIII "num cenário em que ciência e culpa se misturavam, o corpo feminino era visto, tanto por pregadores da Igreja católica quanto por médicos, como um palco nebuloso e obscuro no qual Deus e o Diabo se digladiavam" (Priori, 2006:78). Nesse período, todo o conhecimento científico subjacente ao corpo feminino dizia respeito ao órgão identificado pelo termo madre (útero). Os médicos eram obcecados em 
entender o funcionamento anatômico da madre, mas o olhar funcionalista dirigia-se tão somente ao seu caráter reprodutivo.

Tal conhecimento limitado da anatomia feminina reproduziu um imaginário repleto de simplificações obscuras: o corpo era compreendido como uma espécie de receptáculo de um depósito sagrado que precisava ser fertilizado para frutificar. $O$ saber científico construído sobre pilastras da filosofia e da medicina ocidental da antiguidade relegou o corpo feminino a uma posição de inferioridade em relação ao corpo masculino: "as mulheres só diferiam dos homens por serem machos menos perfeitos, [...] situados hierarquicamente mais abaixo" (Bozon, 2004:36).

Os doutores portugueses continuavam leais "à crença de que o corpo feminino e a procriação eram assuntos divinos, por isso mesmo, irretocável" (Priori, 2006:79). Eles permaneciam presos à premissa de que a natureza feminina, devido à sua fraqueza indiscutível era mais propensa às injunções do demônio. Tal postura era um reflexo das medidas tomadas durante os séculos XVI e XVII pelos jesuítas, o Tribunal do Santo Ofício e a Coroa portuguesa, que somavam forças contra toda e qualquer pioneira iniciativa científica ou cultural, taxando-as de pura heresia.

A coerção eclesiástica inscrevia o discurso médico no dogmatismo do discurso religioso da Igreja, "dentro do qual doença e cura estavam relacionadas ao maior ou menor número de pecados cometidos pelo doente" (Priori, 2006:80). Não por menos, Priori afirma que a falta de conhecimento anatômico e fisiológico amalgamado às fantasias sobre o corpo feminino abriram

espaço para que a ciência médica construísse um saber masculino e um discurso de desconfiança em relação à mulher. A misoginia do período a empurrava para um território onde o controle [de seu corpo] era exercido pelo médico, pai ou marido (Priori, 2006:84). 
Considerando que a ordem, sobretudo das instituições eclesiásticas, era bastante prezada delegou-se à Igreja o exercício da pressão sobre o adestramento da sexualidade da mulher. A superioridade física e social do homem era o argumento utilizado para justificar o paradoxo repressão versus incitação. Segundo Araújo (2006), tal pensamento misógino é expresso claramente no Malleus maleficarum, renomado tratado de demonologia redigido por dois dominicanos alemães, Heinrich Krämer e Jakob Sprenger, que circulou no Brasil colônia:

Houve uma falha na formação da primeira mulher, por ter sido ela criada a partir de uma costela recurva, ou seja, uma costela do peito, cuja curvatura é, por assim dizer, contrária a retidão do homem. E como, em virtude dessa falha, a mulher é animal imperfeito, sempre decepciona a mente (Krämer; Sprenger, 1991:116, apud Araújo, 2006:46).

Assim, coube primariamente às instâncias eclesiásticas instigar e disseminar uma verdadeira explosão discursiva em torno do sexo por meio de alguns documentos básicos de educação feminina como, por exemplo, o estatuto elaborado pelo bispo Azeredo Coutinho, publicado em 1798, cujo objetivo segundo Silva era proteger às meninas "dos defeitos ordinários do seu sexo" (Silva, 1981:68-77 apud Araújo, 2006:50).

Dado que foi a mulher que manteve o primeiro contato com as forças do mal personificadas na serpente do Jardim do Éden, amalgamou-se o estigma da transgressão à natureza feminina. Consequentemente, o peso do pecado original exigia que sua sexualidade fosse policiada e a Igreja atentava para isso no confessionário, vigiando incisivamente gestos, atos, sentimentos $e$ até sonhos, como revelam os manuais de confessores da época que buscavam desvendar

Se pecou com tocamentos desonestos consigo ou com outrem. Se tem retratos, prendas ou memórias de quem ama lascivamente. Se solicitou para pecar com cartas, retratos ou dádivas. Se foi medianeira para isso gente 
maligna que devia ser sepultada viva. Se falou palavras torpes com ânimo lascivo. Se se ornou com ânimo de provocar a outrem a luxúria em comum ou em particular. Se fez jogos de abraços ou outros semelhantes desonestos. Se teve gosto e complacência dos pecados passados ou de sonhos torpes (Ruiz, 1724:447, apud Araújo, 2006:51).

A confissão tinha por objetivo impor às mulheres regras meticulosas de exame e ao mesmo tempo aplicar a penitência das insinuações da carne: "pensamentos, desejos, imaginações voluptuosas, deleites, movimentos simultâneos da alma e do corpo, tudo isso deve entrar, agora, e em detalhe, no jogo da confissão e da direção espiritual" (Foucault, 1988:24). Vale lembrar que as práticas demarcadas como concupiscentes e libidinosas eram reflexo da insatisfação das moças brancas entre 14 e 16 anos que haviam sido coagidas pelos pais a casar-se com homens de trinta, sessenta $e$ até setenta anos. Tais meninas, dominadas $e$ submetidas ao pai, depois de casadas ficavam à mercê de outro senhor: o marido. Nesse contexto o corpo da mulher, sobretudo abastarda, era algo muito descartável. Para copular os homens abaixavam as calças $e$ as mulheres subiam as saias e pronto! Estava tudo resolvido. Esse corpo extremante desvalorizado era acima de tudo aquele submetido à dominação masculina, como muito bem sintetizou Priore:

Juíza da sexualidade masculina, a mulher era ainda estigmatizada com a pecha da insaciabilidade. Seu sexo assemelhava-se a uma voragem, um rodamoinho a sugar desejos $e$ fraquezas masculinos. Unidos, portanto, o horrendo e o fascinante, a atitude ameaçadora da mulher obrigava o homem a adestrá-la. Seria impossível conviver impunemente com tanto perigo, com tal demônio em forma de gente (Priore, 1993:35 apud Araújo, 2006:53).

Contudo, o ideal do controle completo nunca foi alcançado. Apesar dos esforços da Igreja em domar pensamentos e ações, "nem todo mundo aceitava passivamente tamanha interferência 
quando o fogo do desejo ardia pelo corpo ou quando as proibições passavam dos limites aceitáveis em determinadas circunstâncias" (Araújo, 2006:53). Consequentemente, os desvios de norma não eram incomuns, principalmente, entre as mulheres casadas. Paradoxalmente, além do mato, da rede e da cama, a Igreja era um refúgio muito propício ao pecado. Nesse reduto sacrossanto, as mulheres faziam o sinal da cruz e pronunciavam num tom fervoroso as mais ardentes declarações de amor (Araújo, 2006:53).

É bem verdade que a Igreja Católica e os clérigos reconheciam que tanto o homem como a mulher estavam à mercê das tentações e prazeres da carne, $e$, por isso mesmo, não mediam esforços em controlar a vida moral de ambos visando impedir a atividade sexual fora do casamento e limitar marido e esposa apenas às práticas capazes de permitir a inseminação feminina. "No entanto, na prática, e em todas as legislações influenciadas pela [cristandade] (...), o adultério sempre foi visto com um olhar muito mais severo quando dizia respeito às mulheres" (Bozon, 2004:27).

Não obstante, as altas taxas de recém-nascidos deixados nas rodas dos expostos ou enjeitados ${ }^{1}$ alertavam para uma sexualidade ativa, muito diferente daquela que se queria fazer acreditar. As mulheres pobres não foram figuras tão castas $e$ pacatas quanto à historiografia impregnada pelo discurso moralizante ainda insiste em mostrar. Tais mulheres, diferentemente das senhoras e moças da elite cujos comportamentos transgressores foram mais severamente reprimidos, viviam explícitos concubinatos.

\footnotetext{
1 Mecanismo em forma de tambor ou portinhola giratória embutida nas paredes das instituições de caridade cuja finalidade era colocar recém-nascidos que ficariam aos cuidados das instituições de caridade. Tal mecanismo era projetado de tal forma que aquele que expunha a criança não era visualizado por aquele que o recebia.
} 
cadernos pagu (49), 2017:e174922 Implicações da moral religiosa e dos pressupostos científicos na construção das representações do corpo e da sexualidade femininos no Brasi

Ciência e incitação: o escrutínio do corpo e da sexualidade femininos

Diante do estímulo discursivo e da incapacidade prática de conter os desejos da carne, mesmo com a punição severa que incluía a agressão física desmedida e o assassinato das mulheres transgressoras "nasce uma incitação política, econômica, técnica, a falar do sexo. Viu-se a urgente necessidade de 'levar em conta' o sexo, a formular sobre ele um discurso que não [fosse] unicamente o da moral, mas da racionalidade" (Foucault, 1988:27). Dentro dessa concepção emergente, a partir das primeiras décadas do século XIX, os corpos de machos e fêmeas se tornam opostos inquestionáveis, horizontalmente ordenados. Termos foram atribuídos para diferenciar o que até então permanecera confuso.

Obras influentes no período novecentista ao invés de motivar uma revolução nas representações científicas do corpo da mulher impulsionaram reafirmações da sua natureza biológica para desempenhar os papéis de mãe e esposa. Encyclopédie, de Diderot e Alembert, Dictionnaire des sciences medicales de Panckouke, Système physique et moral de la femme, de P. Roussel e Histoire physiologique de la femme, de Lachaise, foram responsáveis pela difusão do determinismo biológico feminino como principal paradigma científico.

De acordo com Rohden, foi nesse cenário que apareceram e consolidaram-se "as especialidades médicas dedicadas exclusivamente às mulheres e à demarcação da diferença baseada no sexo" (Rohden, 2000:84). A ginecologia se constituirá como uma área da medicina voltada exclusivamente para o corpo da mulher e se afirmará a partir da premissa de que o corpo e o papel social femininos dependeriam da função procriativa. Essa ciência não estava interessada na importância do homem na reprodução, mas, sim, em estabelecer uma fronteira bem demarcada entre os dois sexos, alicerçada na afirmação da maternidade como destino da mulher.

Segundo Bozon (2004:37), "ficou, também, estabelecido que o encontro dos espermatozoides com o óvulo poderia se realizar sem o orgasmo feminino, perdendo este último qualquer função 
fisiológica". A irrelevância do orgasmo feminino na reprodução marcará o discurso científico do século XIX em torno da sexualidade feminina. Até o século XVIII, contrariando as teorias aristotélicas e ratificando as teorias hipocratianas, muitos médicos concordavam com o postulado dos espermas masculino $e$ feminino - "sangue elaborado, escumoso e portador de um pneuma” (Seixas, 1998:44). Igualmente, existiam aqueles que não discordavam das mulheres que asseguravam que o esperma produzido por elas provinha do gozo e era imprescindível no momento da fecundação. Para alguns médicos oitocentistas, portanto, não haveria nenhuma procriação sem prazer dividido. Contudo, do século XIX em diante, com o estabelecimento da certeza de que o orgasmo das mulheres era desnecessário no processo fecundativo,
o pudor, a possibilidade da continência sexual, a moderação, a ausência de desejo passaram a ser considerados qualidades naturais [femininas], vinculados à perda da antiga função do prazer feminino. Inversamente, o desejo, a agressividade, e a atividade foram definidos como próprios do indivíduo masculino (Bozon, 2004:37).

Fundem-se, então, "biologização" e "psicologização" da diferença e para percorrer os domínios biológicos e psíquicos mais recônditos da sexualidade $e$, respectivamente, as práticas indiciadas patológicas, a ciência usará o mesmo recurso da igreja: a confissão. Não obstante, não se

\begin{abstract}
trata somente de dizer o que foi feito - o ato sexual - e como; mas de reconstituir nele e a seu redor, os pensamentos $e$ as obsessões que o acompanham, as imagens, os desejos, as modulações e a qualidade do prazer (Foucault, 1988:62).
\end{abstract}

A ciência não tratará tão somente daquilo que o sujeito gostaria de manter oculto, antes focará aquilo que permanece oculto ao próprio sujeito "e que só se pode chegar 
progressivamente e através de uma confissão da qual participam o interrogador e o interrogado, cada um por seu lado" (Foucault, 1988:65). A escuta atenta possibilitou então que no século XIX emergisse uma medicina dedicada ao sexo, apartada da medicina geral do corpo. Essa protosexologia produziu em seus discursos um mapa conceitual da categoria "perversão sexual" que permitiu que fossem especificados os desvios e os processos patológicos considerados degenerativos da espécie humana.

Consequentemente, durante a primeira fase da ciência sexual no Brasil, consolida-se o tripé perversão/hereditariedade/ degenerescência. Os perversos do século XIX ofereciam um grande perigo à sociedade, dado que a degeneração deles poderia ser transmitida para os seus descendentes. Essa lista dos perversos incluía as mulheres pobres e mundanas: prostitutas, masturbadoras, homossexuais, criminosas, ninfomaníacas, neuróticas e histéricas. Tais figuras foram rotuladas também como hipersexuadas. A mulher diagnosticada histérica, por exemplo, foi alvo de grande investimento científico, pois intrigava pela pretendida ânsia sexual e devido à incorporação de uma patologia que curiosamente não deixava rastros físicos. Os médicos explicavam o mal da histeria fazendo referência à natureza feminina, mais especificamente, ao útero e aos nervos.

Percebe-se que o discurso médico hegemônico no século XIX enquadrou as mulheres no âmbito dos maus instintos, convertendo as "particularidades" do seu sexo em anomalias, sinais de uma monstruosidade singular. Elas foram responsabilizadas pela propagação de estigmas psíquicos, físicos e orgânicos degenerativos que deveriam ser higienizados.

Portanto, se durante o Brasil colônia a Igreja interagia com o Estado, após a Independência, a medicina fará isso visando à propagação de seus ideais higienistas, muito úteis ao Estado, pois preencherão a lacuna necessária para sustentar as transformações políticas e sociais imprescindíveis num país liberto. Enquanto na colônia a educação sexual era informal e alicerçada, sobretudo, nos usos e costumes ditados pela Igreja e naqueles que se estabeleciam como populares, no regime imperial e republicano 
ela passou a ser normatizada pela moral médica e documentada em teses, livros e manuais defendidos publicamente (Ribeiro, 2004:17-18).

Vale ressaltar que a construção do saber científico em torno do corpo e da sexualidade femininos no Brasil ocorreu num momento de intensas transformações socioeconômicas. A necessidade de sobrevivência estimulou muitas mulheres pobres a procurar as fábricas e, sobretudo, outras modalidades de trabalho de baixa remuneração no âmbito da economia informal: vendas ambulantes nas ruas e negócios de fundo de quintal (Wissenback, 1988:12). Nesse cenário, no qual a economia informal era subterfúgio seguro, misturavam-se negras quitandeiras e mulheres caipiras nas ruas a vender gêneros alimentícios. Aquelas provenientes das classes média ou alta, por sua vez, lutavam por maiores direitos: exigiam a participação na vida pública e o ingresso nas "profissões masculinas". Enfim, por um motivo ou outro, mulheres pobres e ricas não estavam confinadas somente ao ambiente privado do lar.

Mas ao passo que a mulher timidamente se sobressaía ao adentrar no espaço da vida pública, seu direito de desfrutar experiências privadas era constantemente desrespeitado. As mulheres pobres e carentes testemunhavam a invasão $e$ a destruição dos casebres, cortiços, barracos e mocambos nos quais moravam. Não houve qualquer "hesitação nem sequer em bombardear a matriz da cidade de Canudos, com a população civil de mulheres e crianças que haviam se refugiado no seu interior" (Sevcenko, 1998:30).

\section{Os paradoxos do saber científico envolvendo o corpo e a sexualidade femininos}

O pensamento de Freud irá refletir a ambiguidade de concepções em torno do corpo e da sexualidade femininos que marcou o século XX. Não por menos, os discursos que se tornaram hegemônicos durante a primeira metade do século $\mathrm{XX}$, cujos enunciados foram fundamentados nas mais diversas ciências 
(psicologia, psicanálise, medicina, demografia, antropologia), destacaram a sexualidade da mulher sob a ótica da anormalidade, da frigidez ou da dificuldade em atingir o êxtase sexual.

Numa pesquisa bibliográfica realizada por Reis e Ribeiro (2004), Psiconeuroses e Sexualidade. I - a neurastenia sexual e seu tratamento, publicada em 1919, foi identificada como a obra mais antiga sobre o tema. $\mathrm{O}$ autor desse livro, Antonio Austregesilo, foi professor de clínica neurológica na Faculdade de Medicina do Rio de Janeiro e escreveu várias outras obras sobre a sexualidade, "destacando-se Perfil da mulher brasileira, de 1924, e Conduta sexual de 1934" (Reis; Ribeiro, 2004:28). Nessas referências acadêmicas, Austregesilo discorreu sobre a relação entre a debilidade do sistema nervoso e o aparecimento dos desvios sexuais pautando-se nas terminologias dominantes na época, como, por exemplo, quando afirmou que as moléstias sexuais de modo geral eram decorrentes da insatisfação ou do abuso do instinto sexual, responsáveis pela histeria e pela neurose obsessiva.

Em 1928, Introdução ao estudo da patologia sexual é publicada pelo médico José Albuquerque. Como o próprio título denuncia, o livro aborda as doenças ou afecções estudadas naquele período, atribuídas às causas orgânicas.

\begin{abstract}
Albuquerque define patologia como "perturbações mórbidas da esfera sexual", causadas por um estado de "morbidez geral" e também "o conjunto de fenômenos que se produzem nos órgãos genitais" causados por "morbidez" que atue diretamente sobre os órgãos (Reis; Ribeiro, 2004:30).
\end{abstract}

Em harmonia com os pressupostos freudianos, o médico brasileiro afirmou "que [a ninfomania] é uma afecção sexual que se instala em consequência de lesões orgânicas da medula espinhal" (Rohden:31). Já a frigidez sexual na mulher, segundo Albuquerque, era causada pela dependência de estados disfuncionais metabólicos ou endócrinos. Freud certificou que, de fato, não se podia desconsiderar que as neuroses resultavam 
de distúrbios no metabolismo sexual, seja porque se produzem mais toxinas do que o indivíduo pode metabolizar, seja porque as condições internas, $e$ até mesmo psíquicas, limitam o emprego adequado dessas substâncias (Freud, 1969:452).

Outra referência importante no contexto acadêmico da primeira metade do século XX, no Brasil, foi o médico Hernani do Irajá, autor de dezenas de livros. Em Sexualidade e amor, ele escreveu um ensaio no qual tece opiniões concernentes ao comportamento sexual humano, relata histórias de prostitutas $e$ discorre a respeito do casamento e da decadência do lar.

Já em Psicoses do amor,

apresenta um estudo sobre as perversões sexuais $e$ as anomalias do amor. Dividido em três partes, cada uma com vários capítulos, é um livro denso que trata da forma mais completa possível para a época de todos os assuntos sexuais que eram considerados importantes (Reis; Ribeiro, 2004:31).

No capítulo I da parte I, Irajá trata da origem e do aperfeiçoamento do amor, da fome e do apetite sexual e "discorre sobre as formas de reprodução existentes nos seres vivos e ainda fala da fecundação como um meio de perpetuar a espécie" (Reis; Ribeiro, 2004:31); no capítulo II ele aborda os desvios do instinto natural do amor mórbido e divide em duas grandes categorias distintas as psicopatias sexuais, a saber, hereditárias e adquiridas. As primeiras dizem respeito àquelas que,

desde criança de pouca idade, se mostram diversas de seus congêneres em questões referentes aos desejos sexuais - a anomalia é espontânea e irrefreável. Aquelas que advêm mais tarde e caracterizam os viciados são as adquiridas (Reis; Ribeiro, 2004:45). 
Irajá reserva a parte II de Psicoses do amor, mais especificamente o capítulo I, à discussão das hiperestesias genésicas, ou seja, "os exageros do sentido sexual". Aqui ele afirma "que quando há o exagero do apetite sexual e a pessoa não tem como realizar seu desejo, desenvolve 'as inversões $e$ perversões compensadoras, tais como o homossexualismo e a masturbação"" (Reis; Ribeiro, 2004:46).

Oswaldo Brandão foi outro autor que redigiu obras importantes durante as primeiras décadas do século $\mathrm{XX}$ cujas premissas são conhecidas até os dias atuais. Ele "publicou, em 1938, a obra Iniciação sexual, utilizada por Marilena Chauí em seu livro Repressão sexual: essa nossa (des)conhecida, para ilustrar a normatização da sexualidade como forma de repressão" (Reis; Ribeiro, 2004:51). Assim diz a renomada filósofa sobre o livro de Brandão:

Já na capa do livro observa-se algo interessante. Lê-se: Iniciação Sexual - Educacional (Leitura Reservada). O autor procura, logo de início, esclarecer que não se trata de um livro pornográfico ou obsceno (de sacanagem, diríamos hoje), mas obra educativa. Pressupõe (e explicará tal ideia no decorrer de todo o livro) a distinção entre um sexo "ruim" e um sexo "bom", o que em si mesmo, já é um exemplo de repressão interiorizada (Chauí, 1984:18-19).

Em 1936, Afrânio Peixoto publica Eunice ou a educação da mulher em oposição à vasta literatura de educação sexual voltada para o sexo masculino. Nesse manual o autor realiza uma descrição de cunho biológico e histórica na qual ressalta, respectivamente, a reprodução das espécies como ponto principal da existência do sexo e a educação da mulher desde a antiguidade. Segundo Afrânio Peixoto, é responsabilidade dos pais no âmbito familiar e dos mestres(as) nas escolas educar sexualmente a mulher. Contudo, tal educação deveria enfocar tão somente a preparação para o casamento.

O já citado doutor Albuquerque, por sua vez, em Introdução ao estudo da patologia sexual aborda as patologias sexuais a partir 
de uma ótica de "normalidade/doença em que o ato sexual aceito é aquele realizado dentro do casamento e destinado à procriação e a manter o equilibrio geral do organismo, com indivíduos psiquicamente sadios que desaprovam práticas "anormais e que não padecem das [seguintes] doenças e afecções": masturbação, sexo oral, homossexualismo, bestialidade e o lesbianismo (Reis; Ribeiro, 2004:32).

Se, no final do século XIX, a higienização dos indivíduos e do corpo social foi realizada de modo extremamente impositivo $e$ coercitivo, no século $\mathrm{XX}$, sobretudo no intercurso das cinco primeiras décadas, entre as várias facetas da ideologia do progresso estava aquela que dizia: depende do ser humano o uso da razão durante processo de educação para apreender o modo correto de direcionar sua vida social $e$ íntima em todos os âmbitos de relacionamento, inclusive o sexual. De acordo com esse pressuposto, a prática correta da sexualidade impactaria de modo favorável à marcha nacional rumo ao futuro, à civilidade.

Ao passo que a obstetrícia se preocupa desde sua gênese com a gravidez, o parto e o puerpério, a ginecologia se ocupa da fisiologia e da patologia "dos órgãos genitais da mulher fora da gestação, assim como as suas relações com os restantes aparelhos e sistemas". O Oxford English Dictionary, publicado em 1933, fornece a seguinte definição desse ramo da ciência médica: "trata das funções e perturbações peculiares às mulheres. Em sentido lato, a ciência da feminilidade" (Rohden, 2000:105).

A preocupação da medicina em dedicar-se ao estudo da mulher e não do homem ocorreu num contexto de desigualdades socioeconômicas de gênero muito crítico e por isso mesmo favorável ao afloramento dos ideais feministas. Com a industrialização crescente "as mulheres ganhavam menos que os homens; sofriam de uma dupla jornada de trabalho e não tinham acesso à educação formal e, tal como acontecia com os homens, também não tinham direitos legais, como trabalhadoras" (Mestre, 2004:13). Durante as primeiras décadas do século XX aquelas que empreendiam esforços para espaços além do doméstico pleiteavam para si mesmas elevados índices de discriminação. 
Inquestionavelmente, ao considerar as concepções de Gustavo Capanema, ministro da educação e saúde do governo de Getúlio Vargas de 1934 a 1945, sobre a educação formal que deveria ser destinada a homens e mulheres, identifica-se o pensamento misógino dominante na primeira metade do século $\mathrm{XX}$ :

[...] a educação a ser dada aos dois há, porém, de diferir na medida em que diferem os destinos que a Providência lhes deu. Assim, se o homem deve ser preparado com têmpera de teor militar para os negócios e as lutas, a educação feminina terá outra finalidade que é o preparo para a vida do lar. A família constituída pelo casamento indissolúvel é a base de nossa organização social e por isto colocada sob a proteção especial do Estado. Ora, é a mulher que funda $e$ conserva a família, como é também por suas mãos que a família se destrói. Ao Estado, pois, compete, na educação que lhe ministra prepará-la conscientemente para esta grave missão (Capanema, 1937, apud Schwartzman; Bomeny; Costa, 2000).

Considerando que o social é multifacetado e ambíguo, assim como a comunidade acadêmica brasileira discorreu sobre a importância da educação sexual na contenção das perversões e sublimação do desejo feminino, coube a essa mesma comunidade, juntamente com a elite econômica e cultural, debater temas polêmicos em pauta na agenda feminista. De fato, no decorrer dos anos 20 e 30, proliferou-se no Brasil uma literatura que discutia e questionava a moral sexual não só sob uma ótica conservadora e misógina, mas também em seu sentido oposto, ou seja, anarquista e modernista.

Alguns defensores de ideias mais avançadas sobre a educação sexual "acreditavam que a ignorância masculina com respeito ao corpo $e$ ao funcionamento desejante da mulher resultava em frequentes desentendimentos entre o casal" (Rago, 2002:189). Segundo o médico Olavarrieta, 
a indiferença feminina pelos prazeres sexuais resultava tanto de uma educação errônea, que acentuava sua ignorância em relação às necessidades sexuais e aos deveres conjugais, quanto do egoísmo e do "néscio excesso de pureza" dos maridos. (...) Estes submetiam suas esposas a regimes de relações sexuais extremamente austeros, "transformando as carícias em obrigação, quem sabe em repugnância ou em dor". (...) Para o médico, os homens haviam sido induzidos erroneamente a acreditar que as práticas sexuais prazerosas só poderiam ser consumadas com amigas, amantes ou prostitutas, respeitando religiosamente as esposas (Rago, 2002:189).

Olavarrieta publicou em São Paulo, no ano de 1929, o manual Hygiene Sexual, no qual informava ao público leitor constituído, sobretudo, pelo sexo masculino, a fisiologia tanto do homem quanto da mulher, e esclarecia alguns aspectos importantes para obtenção do prazer sexual de ambos. Todavia, o manual "apresentava-se como um guia para a realização dos prazeres entre o casal, tendo em vista a preservação do casamento" (Rago, 2002:190). Nesse sentido, apesar dos refinados conhecimentos de Olavarrieta e de outros médicos que pensavam de maneira similar, de modo geral, todos ainda estavam mais preocupados com a garantia do casamento e do futuro da descendência do que tão somente com a satisfação das necessidades femininas. "Essencialmente, pregavam a indissolubilidade do matrimônio, embora evidenciando, de modo direto ou indireto, suas angústias e seus temores" (Rago, 2002:192).

Com a inserção de imigrantes nos espaços sociais (principalmente décadas de 1920 a 1940), doutrinas e ideias libertárias e liberais se tornaram também acessíveis à camada das trabalhadoras. Surgiram, então, inúmeras agremiações com esse ideal. Contudo, a principal peculiaridade do movimento feminista nesse período "era o comprometimento com a fidelidade aos princípios da ordem social e o que elas [mulheres] reivindicavam era espaço no mercado de trabalho e igualdade de direitos políticos entre os sexos" (Mendonça \& Ribeiro, 2010). 
Foi somente durante o regime ditatorial no Brasil, na década de 1960, que a presença feminina na luta armada passou a representar uma real transgressão dos papeis de dona de casa, esposa e mãe que sempre foram designados às mulheres. Todavia, a imagem da mulher que continuou a ser construída nesse período ainda era a da "Mulher-Bela-Adormecida", que era exortada a cultivar atitudes decorrentes de um comportamento passivo que amalgamava doses acentuadas de ternura, afetividade a uma pequena pitada de sensualidade.

Não obstante, no decorrer da década de 70 - mais precisamente quando a ONU declara, em 1975, o ano Internacional da Mulher e, no Brasil, é retomado o movimento feminista após maior abertura propiciada pela ditadura militar $^{2}-$ os discursos sobre o corpo $e$ a sexualidade femininos vão adquirindo novos sentidos especialmente sob a influência da chamada "nova sexologia" que ganhou destaque a partir da década de 50 nos Estados Unidos.

Nesse período, sob os pressupostos de Kinsey, proliferam-se nos Estados Unidos as discussões públicas acerca do sexo. Faro discorreu em sua dissertação de mestrado, intitulada $A s$ Disfunções Sexuais Femininas no Periódico Archives of Sexual Behaviors, - sobre as teorias de Kinsey articulando-as ao contexto norte-americano. É importante considerar tal articulação porque as concepções americanas da sexualidade foram exportadas em

2 Durante o governo do general Emílio Garrastazu Médici, que compreende os anos de 1965 a 1974, o Brasil vivenciou o período mais duro e repressivo da ditadura militar, conhecido como "anos de chumbo". Não obstante, a partir de 1975, o general Ernesto Geisel assume a presidência e anuncia a abertura política gradual e segura. Começa, então, um lento processo de transição rumo à democracia. Nesse contexto, o movimento de mulheres organizadas contra a ditadura militar alcançou significativas conquistas. Em 1975, é criado o Centro da Mulher Brasileira (CMB), um órgão institucionalizado que se encarregou de mediar e articular os objetivos feministas em forma de ação coletiva. Nesse mesmo ano, é criado também o Movimento Feminino pela Anistia cujo principal objetivo era denunciar a repressão imposta pelo governo militar aos cidadãos brasileiros. Esse movimento foi muito bem recebido pela sociedade, o que possibilitou o engajamento de muitos grupos políticos e de novas adeptas. 
larga escala para vários países, inclusive para o Brasil. Convém lembrar que estudar a sexualidade no início do século XX não foi para Kinsey uma tarefa fácil. Sobre essa questão, Gagnon se pergunta: "Será que hoje alguém consegue ter uma experiência direta do que deve ter sido, para Kinsey, perambular pelo submundo sexual das décadas de 1940 e 1950, colecionando material erótico?" E logo acrescenta: "Era um mundo em que a pesquisa sobre a sexualidade era um insulto acadêmico" (Gagnon apud Faro, 2008:27).

Vale ressaltar que foram as mudanças notórias nas relações de gênero, nas concepções sobre a sexualidade $e$, consequentemente, nas relações maritais vividas na primeira metade do século $\mathrm{XX}$ que "formaram o pano de fundo que propiciou a viabilização da pesquisa de Kinsey (que começou em 1938) e a receptividade do público ao seu trabalho (o primeiro relatório foi publicado em 1948)" (Faro, 2008:27).

O biólogo estadunidense criticou a

distinção entre comportamento normal ou anormal e
esforçou-se por retirar o caráter patológico de
comportamentos sexuais que fugiam à procriação, o que
incluía a masturbação, relações extra ou pré-maritais $[e]$
contatos homossexuais (Faro, 2008:30).

Desse modo, ele negou que determinados comportamentos sexuais corresponderiam a tipos psicológicos específicos como o pervertido. Por conseguinte, se não havia vinculação direta entre comportamento sexual e estrutura psíquica, não existia também distinção entre o orgasmo resultante de estimulação clitoriana $e$ aquele decorrente de estimulação vaginal.

Nesse sentido, Kinsey se afasta de Freud, que entendia os orgasmos clitorianos como indicadores de uma estrutura psíquica infantil. Esta mesma crítica se aplica à noção freudiana de que a masturbação na vida adulta se relaciona à imaturidade psíquica ou à fixação narcísica da libido. Ao contrário, para Kinsey, a masturbação facilitava a obtenção 
de prazer sexual no intercurso. Isso significou retirar a importância tradicionalmente atribuída ao pênis para o prazer feminino. Kinsey argumentava que as paredes vaginais não são tão sensíveis quanto o clitóris e a genitália externa e, então, transferir o orgasmo clitoriano para a vagina seria uma impossibilidade biológica (Faro, 2008:32).

Mesmo considerando o impacto das afirmações de Kinsey na década de 50 do século XX, "é somente nos inícios dos anos 70 que, no Brasil e em muitos outros países, entra em cena o clitóris, no contexto de toda uma discussão que redefiniu o lugar social e, sobretudo, sexual da mulher" (Rago, 2002:193).

Depois de 1975, as revistas femininas Capricho, Cláudia e Nova não mais instigavam as mulheres a serem "belas adormecidas para o sexo". As mulheres deveriam despertar imediatamente do sono profundo para se deleitarem com as técnicas provenientes do saber da única capaz de garantir orgasmos múltiplos: a sexologia. Essa área de conhecimento, Chauí define como

uma instituição curiosa porque é uma espécie de
combinação do erotismo como arte ou técnica do amor e
da ciência como conhecimento teórico sobre o sexo, sua
atuação mesclando pedagogia e terapia, procurando
substituir a coerção pela informação correta (Chauí,
1984:171).

A autora parece compartilhar da mesma opinião dos críticos que, segundo ela, "consideram os sexólogos uma mescla de pedagogo e de programador de computador, médico e higienista e uma nova figura da repressão sexual" (Chauí, 1984:21-22), pois o orgasmo para eles deixou de ser um direito e se tornou um dever. De modo irônico e até sarcástico, ela refere-se à sexologia nos seguintes termos:

Combina medicina e psicologia comportamental, parte de um estudo das doenças sexuais físicas e de comportamento, 
propõe um tratamento rápido (mínimo de uma semana $e$ máximo de um mês), promete o orgasmo perfeito, tolera o homossexualismo, recomenda a masturbação e defende a democracia sexual (direito e dever de orgasmo para todos). Trabalha com as ideias de função adequada e disfunção (as disfunções principais são: impotência, frigidez, ejaculação precoce e ausência de ejaculação), atribuindo estas a maus condicionamentos ou condicionamentos inadequados do comportamento (a terapia consistindo em mudar os condicionamentos e obter a funcionalidade) e recomenda medidas de higiene e profilaxia, pois com elas o orgasmo pode começar muito cedo e terminar muito tarde, não havendo necessidade de aguardar o momento de iniciar a vida sexual nem de interrompê-la - juventude e velhice não têm valor para a orgasmoterapia (Chauí, 1984:171-172).

\section{Considerações finais}

Atualmente vivemos uma época na qual as concepções sexológicas se tornaram hegemônicas. $\mathrm{O}$ que se observa nas falas cotidianas das pessoas revela que muitas parecem não discordar da democracia sexual que apoia-se em três ideias bastante específicas e caras desde as últimas décadas do século XX até hoje:

a primeira é a do altruísmo social (donde o dever de produzir orgasmo no parceiro); a segunda, é a do direito à felicidade (donde o dever de obter seu próprio orgasmo); a terceira, inclui as virtudes públicas: tolerância, racionalidade (as relações sexuais devem ser refletidas, calculadas, decididas e programadas segundo seus custos e vantagens, aceitação da opinião pública (no caso, a dos especialistas) $e$ liberdade de expressão sexual (na medida em que a liberdade de expressão é um dos direitos fundamentais do homem e do cidadão) (Chauí, 1984:171-172).

As mulheres modernas acabaram sendo condicionadas a pensar que "a sexualidade se reduz ao ato do orgasmo", considerado por elas sob o prisma da "democracia sexual", portanto, um direito que lhes é devido. Além do mais, elas 
acreditam veementemente que para serem felizes e sexualmente realizadas precisam de muitos e bons orgasmos, ou seja, precisam inquestionavelmente de prazer. Esses valores globalmente disseminados, que circundam a sexualidade feminina no século XXI, são frutos do processo de personalização que envolveu todas as sociedades influenciadas pela cultura ocidental hedonista, dentre elas a sociedade brasileira.

Para Lipovetsky (2005), tal processo pode ser compreendido como um tipo de controle social que nos arrancou da ordem disciplinar-revolucionária-convencional que predominou até os anos cinquenta, em muitos países desenvolvidos, e, no Brasil, até os anos 70. Logo, o "processo remete para a fratura da socialização disciplinar" e "corresponde à instalação de uma sociedade flexível assente" tanto na informação e na estimulação das necessidades como no sexo. Caracteriza-se ainda pelo culto exacerbado da libertação pessoal, ou seja, "viver livre e sem coação, escolher sem restrições o seu modo de existência" (Lipovetsky, 2005:9-10). Segundo esse mesmo autor, não há outro fato social mais significativo e nem aspiração $e$ desejo mais legítimo do que esse aos olhos dos nossos contemporâneos: o direito a liberdade ilimitada.

Assim, a vida libertária ocupa "o lugar da retórica do dever; os temas da livre manifestação individual e emancipação sexual tomaram a dianteira em relação aos parâmetros de virtude". Se outrora 'dever' "era um termo que se escrevia com letras maiúsculas; hoje grafa-se com minúsculas" e predomina "uma sincrética conciliação entre dever e prazer". De fato, "em poucas décadas, passamos de uma civilização do dever a uma cultura da felicidade subjetiva", uma cultura do prazer (Lipovetsky, 2005:2530).

Em decorrência disso, "promoção de valores liberais na vida particular" e "felicidade acima de tudo" são lemas imperativos na cultura pós-moderna. Consequentemente, "a sufocante ideologia que orienta nossa época" pode ser compreendida como "pósmoralista, porque é predominantemente baseada nas coordenadas da felicidade e da auto-realização". Desse modo, "edificou-se uma 
nova civilização, não mais voltada para refrear o desejo, mas, ao contrário, para levá-lo à sua exacerbação extrema, despojando-o de qualquer conotação negativa" (Lipovetsky, 2005:29-31). A revolução clitoriana $e$ a orgasmoterapia são produtos da promoção dos valores hedonistas propagados pelo processo de personalização que culminou na liberação sexual e na revolução completa da moral sexual tradicional.

O binômio sexo-pecado relegava o corpo a uma condição decaída e as restrições concernentes à excitação do corpo feminino se tornaram inúmeras. Mas com a consolidação do binômio sexo-prazer, o corpo feminino deixou de ser território interditado. Ele deve ser explorado pelo homem e pela própria mulher através das preliminares e das técnicas masturbatórias.

Segundo os sexólogos, a masturbação é muito eficaz no tratamento das disfunções orgásticas e quando eles descrevem a base teórica para usá-la nesse tratamento, alguns argumentos são apresentados:

produz os orgasmos mais intensos [...]; há sugestões de que um orgasmo intenso produz um aumento na vascularização da vagina, lábios e clitóris. Supõe-se que este aumento na vascularização leve, por sua vez, a uma melhora do potencial de orgasmos futuros (Faro, 2008:73).

Segundo Faro (2008:88), a dor genital no ato da relação sexual ou das atividades costumeiras do cotidiano igualmente preocupava os médicos responsáveis ou não pelos transtornos sexuais, sobretudo, a partir da segunda metade do século XX. Se a dor fosse exclusivamente decorrente dos efeitos "fisiológicos de uma condição médica geral e causasse sofrimento acentuado ou dificuldade interpessoal, deveria ser classificada como "dispareunia" e ser tradada, afinal, a dor inibe o prazer e essa ideia era inconcebível.

Pode-se, então, afirmar que a ordem científica moderna aposta na transformação de todas as práticas corporais, sobretudo sexuais, em experiências visando à busca dos prazeres ilimitados. 
Esta busca defende que é preciso viver em meio a prazeres constantes $e$ acumular prazeres suplementares: por conseguinte, se no tempo de nossos avós nós nos arrependíamos dos prazeres furtivamente experimentados sem o consentimento da bíblia ou da igreja, há, hoje, a tendência em se arrepender dos prazeres eventualmente não vividos: o passado continua a perseguir cada um mas com outras exigências (Sant'anna, 2005:4-5).

Enfim, fazendo minhas as palavras de Sant'anna:

o poder que investe no controle e na estimulação constantes do corpo torna o próprio prazer uma ordem sem exceção. Entretanto, os fantasmas do par 'controleestimulação' não poderiam deixar de ser, justamente, a ameaça do descontrole e o pavor diante da desestimulação (Sant'anna, 2005:4-5).

\section{Referências bibliográficas}

ARAÚJO, Emanuel. A arte da sedução: sexualidade feminina na colônia. In: PRIORI, Mary Del (org.). História das mulheres no Brasil. $8^{\mathrm{a} e d .}$ São Paulo, Contexto, 2006, pp.45-77.

Barbosa, E. T. R.; Brandão, R. B. A.; Telecio, R. F. As múltiplas faces do movimento feminista nas décadas de 60 e 70 no Brasil. In: III Seminário Nacional - Gênero e Práticas Culturais: Olhares Diversos Sobre a Diferença. 2011, João Pessoa [<http://www.itaporanga.net/genero/3/09/04.pdf $>$ - Acesso em: 10 jan. 2012].

Bozon, Michel. Sociologia da sexualidade. Rio de Janeiro, Editora FGV, 2004.

CHAUí, Marilena. Repressão sexual: essa nossa (des)conhecida. São Paulo, Editora Brasiliense, 1984.

COELHO, E. C. As profissóes imperiais: medicina, engenharia e advocacia no Rio de Janeiro1822-1930. Rio de Janeiro, Record, 1999. 
COLLING, Ana Maria. O corpo que os gregos inventaram. In: STREY, M.

$\mathrm{N}$; CABEDA, S.T.L. (org.). Corpos e subjetividade em exercício interdisciplinar. Porto Alegre, EDIPUCRS, 2004, pp.49-64.

DONZELOT, Jacques. A polícia das famílias. $2^{\mathrm{a}}$ ed. Rio de Janeiro, Edições Graal, 1986.

FARO, Livi Ferreira Testoni de. As disfunções sexuais femininas no periódico Archives of Sexual Behavior. Dissertação (Mestrado em Saúde Coletiva) - Programa de Pós-Graduação em Saúde Coletiva, Instituto de Medicina Social da Universidade do Estado do Rio de Janeiro, Rio de Janeiro, 2008.

FouCAult, Michel. História da sexualidade 1: a vontade de saber. $9^{\mathrm{a} e d .}$ Rio de Janeiro, Graal, 1988.

. O corpo dos condenados. In: Vigiar e punir: nascimento da prisão. 13ª ed. Petrópolis, Vozes, 1996.

FREUD, Sigmunt. Obras completas de Sigmund Freud. Vol. XVI. Rio de Janeiro, Imago Editora Ltda., 1969.

GAGNON, John H.. Uma interpretação do desejo: ensaios sobre o estudo da sexualidade. Rio de Janeiro, Garamond, 2006.

GARCIA, Wilton (org.). Corpo e subjetividade: estudos contemporâneos. São Paulo, Factash Editora, 2006.

GIDDENS, Anthony. As transformaçôes da intimidade: sexualidade, amor \& erotismo nas sociedades modernas. $2^{\mathrm{a}}$ ed. São Paulo, Editora da Universidade Estadual Paulista, 1992. 2002.

Modernidade e identidade. Rio de Janeiro, Jorge Zahar Ed.,

GOFFMAN, Erving. Estigma: notas sobre a manipulação da identidade deteriorada. $4^{\mathrm{a}}$ ed. Rio de Janeiro, Guanabara, 1988.

HEILBORN, Maria Luiza et. al. O aprendizado da sexualidade: reprodução e trajetórias sociais de jovens brasileiros. Rio de Janeiro, Garamond e Fiocruz, 2006.

Helman, Cecil G. Cultura, saúde \& doença. $4^{\mathrm{a} e d}$. São Paulo, Artmed Editora S.A, 2008. 
cadernos pagu (49), 2017:e174922 Implicações da moral religiosa e dos pressupostos científicos na construção das representações do corpo e da sexualidade femininos no Brasi

Holzmann, Liza. Histórias de vida e depoimentos pessoais. vol. 2 , $\mathrm{n}^{\circ} 1$, 2002, pp.44-56 [https:/www.revista2.uepg.br - acesso em: fev. 2012].

ILliCH, Ivan. $A$ expropriação da saúde: nêmesis da medicina. $4^{\mathrm{a} E}$ d. Rio de Janeiro, Editora Nova Fronteira S.A, 1975.

JODELET, Denise (org.). As representaçôes sociais. Rio de Janeiro, EdUERJ, 2001.

KNAUTH, Daniela R. Psicoterapia, depressão e morte no contexto da AIDS. In: AlveS, Paulo C.; RABELO, Miriam C. (org.). Antropologia da saúde: traçando identidade e explorando fronteiras. Rio de Janeiro, Fiocruz, Relume-Dumará, 1998, pp.139-156.

Lebreton, David. Adeus ao corpo. Campinas, SP, Papirus, 2003.

. A sociologia do corpo. Petrópolis, RJ, Vozes, 2006.

LIMA, Lana L. G. Confissão e sexualidade. In: VAINFAS, Ronaldo. História e sexualidade no Brasil. Rio de Janeiro, Graal, 1986, pp.78-79.

LIPOVETSKY, Gilles. A sociedade pós-moralista: o crepúsculo do dever e a ética indolor dos novos tempos democráticos. Barueri, São Paulo, Manole, 2005.

- A felicidade paradoxal: ensaio sobre a sociedade de hiperconsumo. São Paulo, Companhia das Letras, 2007a.

. A sociedade da decepção. Barueri, SP, Manole, $2007 \mathrm{~b}$.

LOYOLA, Maria Andréa. A antropologia da sexualidade no Brasil. PHISIS: Revista de Saúde Coletiva, Rio de Janeiro, 2000, vol. 10, $\mathrm{n}^{\circ} 1$, pp.143-167.

MATTOS, Sônia Missagia de. Gênero, uma possibilidade de interpretação. Caderno Espaço Feminino, Universidade Federal de Uberlândia, vol. 10, n¹2/13, Jan/Dez 2003.

MENDONÇA, J.G.R; RIBEIRO, P.R.M. Algumas reflexões sobre a condição da mulher brasileira da colônia às primeiras décadas do século XX. Revista Ibero-Americana de Estudos em Educação, UNESP, Araraquara, vol. 5, n 1, 2010, pp.93-104.

MESTRE, Marilza Bertassoni Alves. Mulheres do século XX: memórias de trajetórias de vida, suas representações (1936-2000). Tese 
(Doutorado em História) - Universidade Federal do Paraná, Rio de Janeiro, Paraná, 2004.

MURARO, Rose Marie. Sexualidade da mulher brasileira: corpo e classe social no brasil. Petrópolis, Vozes, 1983.

PAIVA, Vera. Sexualidade e gênero num trabalho com adolescentes para prevenção do HIV/AIDS. In: PARKER, R.; BASTOS, C.; GALVÃO, J.; PEDROSA, J. S. (org.). A AIDS no Brasil (1982-1992). Rio de Janeiro, Relume Dumará, 1994, pp.231-250.

PARKER, Richard. Corpos, prazeres e paixóes: a cultura sexual no Brasil contemporâneo. $3^{\mathrm{a}}$ ed. São Paulo, Editora Best Seller, 1991.

Parker, R.; Bastos, C.; Galvão, J.; Pedrosa, J. S. (Org.). a AIDS no Brasil (1982-1992). Rio de Janeiro, Relume Dumará, 1994.

PRIORI, Mary Del (Org.). História das mulheres no Brasil. $8^{\mathrm{a} e d .}$ São Paulo, Contexto, 2006a.

PRIORI, Mary Del. História do amor no Brasil. $2^{\mathrm{a} e d . ~ S a ̃ o ~ P a u l o, ~ C o n t e x t o, ~}$ 2006b.

RAGO, Margareth. Os mistérios do corpo feminino, ou as muitas descobertas do "amor venéris". Projeto História, vol. 25, PUC-SP, São Paulo, 2002, pp.181-195 [https://www.revistas.pucsp.br - acesso em: jan. 2012].

REIS, G. V; RIBEIRO, P. R. M. A institucionalização do conhecimento sexual no Brasil. In: RiBEIRO, Paulo Rennes Marçal (org.). Sexualidade e educação: aproximações necessárias. São Paulo, Arte \& Ciência, 2004, pp.27-72.

RIBEIRO, Paulo Rennes Marçal (Org.). Sexualidade e educação: aproximações necessárias. São Paulo, Arte \& Ciência, 2004.

ROHDEN, Fabíola. Uma ciência da diferença: sexo, contracepção e natalidade na medicina da mulher. Tese (Doutorado em Antropologia) - Museu Nacional, Universidade Federal do Rio de Janeiro, Rio de Janeiro, 2000.

Rougemont, Denis. $O$ amor e o ocidente. Rio de Janeiro, Editora Guanabara S.A, 1988.

SANCHES, F. J. B; PARRA, H. Z. M.; MELO, J. L. Olho no olho: repressão, solidariedade e comunicação. In: MARTINS, José de Souza (org.). 
Vergonha e decoro na vida da metrópole. São Paulo, Hucitec, 1999, pp.73-86.

SANT'ANNA, Denise Bernuzzi. Transformações do corpo: controle de si e uso dos prazeres. In: Rago, M.; ORLANDI, L. B. L.; Veiga-Neto, A. (orgs.). Imagens de Foucault e Deleuze: ressonâncias nietzschianas. Rio de Janeiro, DP\&A, 2005, pp.99-110.

Schwartzman, S; Bomeny, H. M. B.; CostA, V. M. R. Tempos de Capanema. $2^{\mathrm{a}}$ ed. São Paulo, Fundação Getúlio Vargas e Editora Paz e Terra, 2000.

SEIXAS, Ana Maria Ramos. Sexualidade feminina: história, cultura, família, personalidade \& psicodrama. São Paulo, Editora SENAC, 1998.

SevCEnKo, Nicolau (org.). História da vida privada no Brasil 3. São Paulo, Companhia das Letras, 1998.

VenÂNCIO, Renato Pinto. Maternidade negada. In: Del PRIORE, Mary (org.). História das mulheres no Brasil. $8^{\mathrm{a}}$ ed., São Paulo, Contexto, 2006, pp.189-222.

WEEKS, Jeffrey. O corpo e a sexualidade. In: LOURO, Guacira Lopes (org.). O corpo educado: pedagogias da sexualidade. $2^{\mathrm{a}}$ ed. Belo Horizonte, Autêntica, 2001.

WISSENBACK, Maria Cristina Cortez. Da escravidão à liberdade: dimensões de uma privacidade possível. In: SEVCENKO, Nicolau (org.). História da vida privada no Brasil 3. São Paulo, Companhia das Letras, 1998, pp.49-130.

XAVIER FILHA, Constantina. A sexualidade feminina entre práticas divisoras: da mulher "bela adormecida" sexualmente à multiorgástica - imprensa feminina e discursos de professoras. GT: Gênero, Sexualidade e Educação, $\mathrm{n}^{\circ}$ 23, DED-PPGEdu/UFMS, 2012 [<http://www.anped.org.br/reunioes/30ra/trabalhos/gt23-3297-int.pdf $>$ - acesso em: 8 jan. 2012]. 